\title{
Thermal Decomposition Kinetics of Core-shell Structured Wood-plastic Composites: Effect of White Mud Loadings on the Shell Layer
}

\author{
Yu Xian, ${ }^{\mathrm{a}, \mathrm{b}}$ Cuicui Wang, ${ }^{\mathrm{b}}$ Ge Wang, ${ }^{\mathrm{b}}$ Leemiller Smith, ${ }^{\mathrm{c}}$ and Haitao Cheng ${ }^{\mathrm{b}, *}$ \\ This study inspected the thermal decomposition kinetics of core-shell \\ structured wood-plastic composite material with white mud loading in the \\ shell. The thermal decomposition was studied via thermogravimetric \\ analysis under nitrogen atmosphere. Experiments were performed at \\ different heating rates of $5,10,20,30$, and $40^{\circ} \mathrm{C} / \mathrm{min}$ from ambient \\ temperature to $700^{\circ} \mathrm{C}$. Multivariate linear regression analysis was applied \\ to estimate the activation energy with the Flynn-Wall-Ozawa method, and \\ the thermal aging life equations of composites were obtained as described \\ in ASTM E1877 (2000). The results showed that the combustion \\ characteristic parameters $\left(T_{5 \%}, T_{\mathrm{p} 1}, T_{\mathrm{p} 2}\right.$, and $\left.T_{\mathrm{p} 3}\right)$ increased at first and then \\ decreased with increased white mud concentration. Accordingly, the \\ average apparent activation energy $\left(E_{\mathrm{a}}\right)$ values of thermal decomposition \\ with conversion rates ranging between $20 \%$ and $80 \%$ were $222 \mathrm{~kJ} / \mathrm{mol}$ for \\ high-density polyethylene (HDPE) shell layer and the average values of \\ $201,226,201,207$, and $223 \mathrm{~kJ} / \mathrm{mol}$ were achieved with white mud loading \\ of $5,10,15,20$, and $25 \%$ in the shell layer, respectively. There were no \\ remarkable dependencies among them. The service life $t_{f}(\mathrm{~min})$ and the \\ service temperature $T(\mathrm{~K})$ of the core-shell structured wood-plastic \\ composites were experimentally determined.
}

Keywords: Core-shell structure; Wood-plastic composites; Thermal analysis; Kinetics; Thermal aging life

Contact information: a: The College of Forestry, Shanxi Agricultural University, Taigu, Shanxi, China; b: International Centre for Bamboo and Rattan, Beijing, P. R. China, 100102; c: Mechanical Energy

Engineering Department, University of North Texas, Denton, TX 76207-7102, USA;

*Corresponding author: htcheng@icbr.ac.cn

\section{INTRODUCTION}

Natural fiber-reinforced common polymer matrixes are increasingly used due to their low cost, high modulus of elasticity, abundant availability, biodegradability, and low density (Mohanty et al. 2018). Natural fibers are an environmentally friendly and renewable resource that can be used as a replacement for glass fibers or other synthetic fibers. These natural fiber-containing composites with excellent properties can be used in varied applications. Wood-plastic composites offer especially promising properties (Yi et al. 2017; Dun et al. 2019). Compared with plastics and wood products, wood-plastic composites have improved thermal properties, physical mechanics, creep performance, and enhanced durability. However, the qualities of wood-plastic composites are affected by aging problems and low thermostability that decrease their useful life. Hence, it is important to further improve their physical and mechanical properties to meet the needs of various applications. The use of optimized composition and the co-extrusion process are simple and effective methods to improve the overall performances of wood-plastic composites (Kim 2014). 
Inorganic particles and fibers are usually used to enhance the shell layer of coextruded wood-plastic composites. Incorporation of inorganic particles in plastics can be favorable to save the cost of raw materials and improve modulus and strength (Mittal et al. 2019). In wood-plastic composites, inorganic particles can enhance physical and mechanical properties (Ismaeilimoghadam et al. 2016). For example, the use of talc in the shell layer positively affected the modulus, strength, and linear coefficient of thermal expansion values in coextruded wood-plastic composites (Huang et al. 2015). Liu et al. added nanosilica to the shell layer and found improved weatherability of coextruded woodplastic composites and well-maintained mechanical properties (Liu et al. 2019). More recently, Hao et al. (2019) showed that incorporation of nano-scale size silica particles filled shells improved the flexural properties, impact strength, and creep behavior of coextruded wood fiber/plastic composites (WF/HDPE). The authors previously demonstrated improved strength and toughness of bamboo fiber reinforced plastic composites after the addition of white mud in wood-plastic composites and coextruded wood-plastic composites (Ren et al. 2014; Xian et al. 2016). The presence of white mud in the shell layer may also improve the thermal stability of core shell structured wood-plastic composites.

Wood-plastic composites are easily degraded and aged when exposed to light, heat, and oxygen, which limits their application as a construction material (Friedrich 2019). TranVan et al. (2014) evaluated the thermal decomposition kinetics of dry balsa and hygroscopic-aged balsa wood using the Kissinger method, and they found that the moisture content affected the activation energy and other kinetic parameters. Sun et al. (2016) analyzed the activation energy required for the pyrolysis of different composites and found higher activation energy values for wood flour/polypropylene composites containing magnesium hydroxide, expandable graphite, and ammonium polyphosphate than those for composites containing magnesium hydroxide, expandable graphite, and ammonium polyphosphate. Satapathy and Kothapalli (2018) reported that the incorporation of fly ash cenospheres increased the thermal stability of banana fiber/recycled high-density polyethylene composites. Constante and Pillay (2017) evaluated the thermal degradation of algae fiber and grafted polypropylene composites by solid state kinetic models, and found the Avrami-Erofe'ev model provided the best statistical fit for the degradation process.

Bamboo residue fibers and white mud are solid residues produced when bamboo is used for pulping and papermaking. White mud is an inexpensive material for use as filler and has large amounts of calcium carbonate (Li et al. 2012). Recent studies revealed that the addition of white mud into high-density polyethylene (HDPE)/polypropylene (PP) matrix improved the mechanical properties of the resulting composites (Xian et al. 2018). In the authors' previous work, white mud was successfully utilized as a second filler in a bamboo flour/HDPE blend matrix; the obtained composites exhibited remarkably increased mechanical, thermal, and dynamic mechanical properties compared to control samples (Xian et al. 2015). Further investigation and detailed analysis on wood fiber/polymer composite systems filled with natural industrial wastes are required to assess the usefulness of these composite materials for specific applications. In this study, the authors evaluated the use of white mud from bamboo pulp residue and the effect of white mud loading on the thermal stability and degradation kinetics of core-shell structured wood-plastic composites. 


\section{EXPERIMENTAL}

\section{Materials}

The bamboo residue fiber and the white mud studied in this paper were collected from Guizhou Chitianhua Co., Ltd. (Guizhou, China). The bamboo residue fibers were oven-dried at $80{ }^{\circ} \mathrm{C}$ for $24 \mathrm{~h}$ before mixing with HDPE. White mud was further processed into a fine power of 800-mesh before blending with other materials. The composition of white mud is given in Table 1. PE-Wax purchased from the Yi-li Chemical Reagent Company (Beijing, China) was used as lubricant. High-density polyethylene (HDPE) DGDK-3364 grade for extrusion molding was delivered by Zhangmutou Plastic Co., Ltd. (Guangzhou, China), with a density of $0.945 \mathrm{~g} / \mathrm{cm}^{3}$, melt mass-flow rate of $0.75 \mathrm{~g} / 10 \mathrm{~min}$ $\left(190{ }^{\circ} \mathrm{C}, 2.16 \mathrm{~kg}\right)$, and a tensile strength of $22.1 \mathrm{MPa}$. The compatibility of fiber/plastic blends was maleated polyethylene (MAPE, CMG9801), which was supplied by the Zhang $\mathrm{Mu}$ Tou Co., Ltd. (Guangzhou, China). White mud and HDPE were used as the shell systems, HDPE and bamboo residue fiber were used for core systems. All the systems used a twin-screw extruder (KS20; Kunshan Kexin Rubber Plastic Machinery Co., Ltd., Kunshan, China) to mix granulation before co-extrusion at $150{ }^{\circ} \mathrm{C}, 160{ }^{\circ} \mathrm{C}, 165{ }^{\circ} \mathrm{C}, 175$ ${ }^{\circ} \mathrm{C}$, and $150{ }^{\circ} \mathrm{C}$ (die).

Table 1. Chemical Composition of White Mud (wt\%) (Xian et al. 2015)

\begin{tabular}{|c|c|c|c|c|c|c|}
\hline $\mathrm{CaCO}_{3}$ & $\mathrm{CaO}$ & $\mathrm{SiO}_{2}$ & $\mathrm{Fe}_{2} \mathrm{O}_{3}$ & $\mathrm{NaOH}$ & Acid-insoluble & Other \\
\hline 87.97 & 1.07 & 2.82 & 0.3 & 0.7 & 1.76 & 3.4 \\
\hline
\end{tabular}

Manufacturing of core-shell structured wood-plastic composites

The composites were prepared using co-extrusion technology. The core system was made by single screw extruder (SJ30; Shanghai Sunlight Plastic Machinery Manufacturing Co., Ltd., Shanghai, China) with a diameter of $30 \mathrm{~mm}$. The shell system was made using a 20-mm single screw extruder (SJ20; Shanghai Sunlight Plastic Machinery Manufacturing Co., Ltd., Shanghai, China). The co-extrusion system employed a special-designed die. The cross-section area was $4 \times 30 \mathrm{~mm}^{2}$. The thickness of the core and shell layer were determined by the rotational speed of the screw. Based on preliminary tests, the ratio rotational speed of core-shell system was set as 1/2. Extrusion temperatures of the core system used were $160{ }^{\circ} \mathrm{C}, 165^{\circ} \mathrm{C}, 170{ }^{\circ} \mathrm{C}, 170{ }^{\circ} \mathrm{C}$, and $165^{\circ} \mathrm{C}$ (die), and a range from 160 to $180{ }^{\circ} \mathrm{C}$ for shell formulations. The core shell structured wood-plastic composites were cooled using 2-m cooling slots with controlled water flowing. Extrusion speed was maintained using a speed-controlled puller. Additional details of the manufacturing process were previously published (Yao and $\mathrm{Wu} 2010$ ). White mud was filled at 0\%, 5\%, 10\%, $15 \%, 20 \%$, and $25 \%$ in the shell layer, and the resulting composites were designated as CSHDPE, CSWM5, CSWM10, CSWM15, CSWM20, and CSWM25, respectively.

\section{Methods}

\section{Apparatus and methodology}

The thermal decomposition of core-shell structured wood-plastic composites was performed with a thermo gravimetric analyzer (TGA) Q500 (TA Instruments Inc., New Castle, DE, USA). Thermal decomposition was measured as global mass loss. This TGA system detected mass variations as little as $0.1 \mathrm{mg}$ as a function of temperature. Specimens were monitored for thermal decomposition at heating rates of $10,20,30$, and $40{ }^{\circ} \mathrm{C} / \mathrm{min}$ 
over the range of 25 to $800{ }^{\circ} \mathrm{C}$. The discussed curves and results correspond to one measurement performed at each heating rate. The thermal degradation behavior of coreshell structured wood-plastic composites was studied under a nitrogen atmosphere. To ensure accurate data, the samples for TGA runs were taken from cross section including core and shell layer materials based on the slice method. About $10 \mathrm{mg}$ of composites was placed into a ceramic sample pan.

\section{Theoretical Section}

Flynn-Wall-Ozawa model

The Flynn-Wall-Ozawa (FWO) method was used to calculate the kinetic parameters of the thermal decomposition (Masawat et al. 2019). According to the principles of the method, the following expression can be obtained,

$$
\begin{aligned}
& \mathrm{d} \alpha / \mathrm{d} t=k(T) \times f(\alpha) \\
& k(T)=A \exp \left[-E_{\mathrm{a}} /(R T)\right] \\
& \alpha=\left(m_{0}-m_{\mathrm{t}}\right) /\left(m_{0}-m_{\mathrm{f}}\right) \times 100 \%
\end{aligned}
$$

where $\alpha$ is the degree of conversion $(\%), k(T)$ is introduced by replacing the Arrhenius Eq. 2, $f(\alpha)$ is the reaction model, which is dependent on the temperature of process rate, $A$ represents the pre-exponential factor $\left(\mathrm{min}^{-1}\right), E_{\mathrm{a}}$ represents the apparent activation energy $\left(\mathrm{kJ} \mathrm{mol}^{-1}\right), R$ is the gas constant $(8.314 \mathrm{~J} /(\mathrm{mol} \cdot \mathrm{K})), T$ is the absolute temperature $(\mathrm{K}), m_{0}$, $m_{\mathrm{t}}$, and $m_{\mathrm{f}}$ represent the initial weight $(\mathrm{mg})$, the weight $(\mathrm{mg})$ at the temperature $T$ and the final weight $(\mathrm{mg})$ at the end of experiments, respectively. To analyze a dynamic TGA process in a non-isothermal experiment, the heating rate, $\beta=\mathrm{d} T / \mathrm{d} t$, into Eqs. 1 to 3 is obtained as:

$$
\mathrm{d} \alpha / \mathrm{d} T=(A / \beta) \times \exp \left[-E_{a} /(R T)\right] \times f(\alpha)
$$

Equations 2 and 3 are the fundamental equations of the analytical methods that can be used to calculate the kinetic parameters from the TGA results. The FWO method is a model-free method to evaluate the kinetics of biomass pyrolysis without modelistic assumptions. On the basis of Doyle's approximation, this method can be expressed as follows:

$$
\log \beta=\log \left[A E_{a} / R f(\alpha)\right]-2.315-0.4567 E_{\mathrm{a}} / R T
$$

For a given conversion rate, a linear relationship is observed from the plot of $\log \beta$ vs. 1/T. The apparent activation energy is obtained from the slope of the curve (Origin, OriginLab, v.9.1, Northampton, MA, USA).

\section{RESULTS AND DISCUSSIONS}

\section{Thermogravimetric Analysis of Core-shell Structured Wood-plastic Composites}

Figures 1a and $\mathrm{b}$ show the profiles of relative mass loss (TG) and mass loss rate (DTG) of core-shell structured wood-plastic composites under nitrogen atmosphere, for different white mud loading in the shell layer at $10^{\circ} \mathrm{C} / \mathrm{min}$. The TG and DTG curves show almost the same trend, regardless of the white mud addition, which indicates that the composites went through a similar pyrolysis process due to the same chemical bonds in 
their molecular structures. The thermal decomposition of core-shell structured woodplastic composites is generally divided into three stages. This can be confirmed by the presence of three steps in the TG curves and the three peaks in DTG curves. The first step was mainly the decomposition of cellulose and hemicellulose that extended from 200 to $400{ }^{\circ} \mathrm{C}$, and there was a rapid loss of weight. The second step was the decomposition of HDPE in 400 to $500{ }^{\circ} \mathrm{C}$, which was the rapid loss of weight during the pyrolysis of composites. The third stage was from $600{ }^{\circ} \mathrm{C}$ to $700{ }^{\circ} \mathrm{C}$, corresponding to the combustion of white mud, a small peak occurred in the DTG curve. The burnout of fixed carbon was also in this stage. The combustion was completed at the end of the third stage.

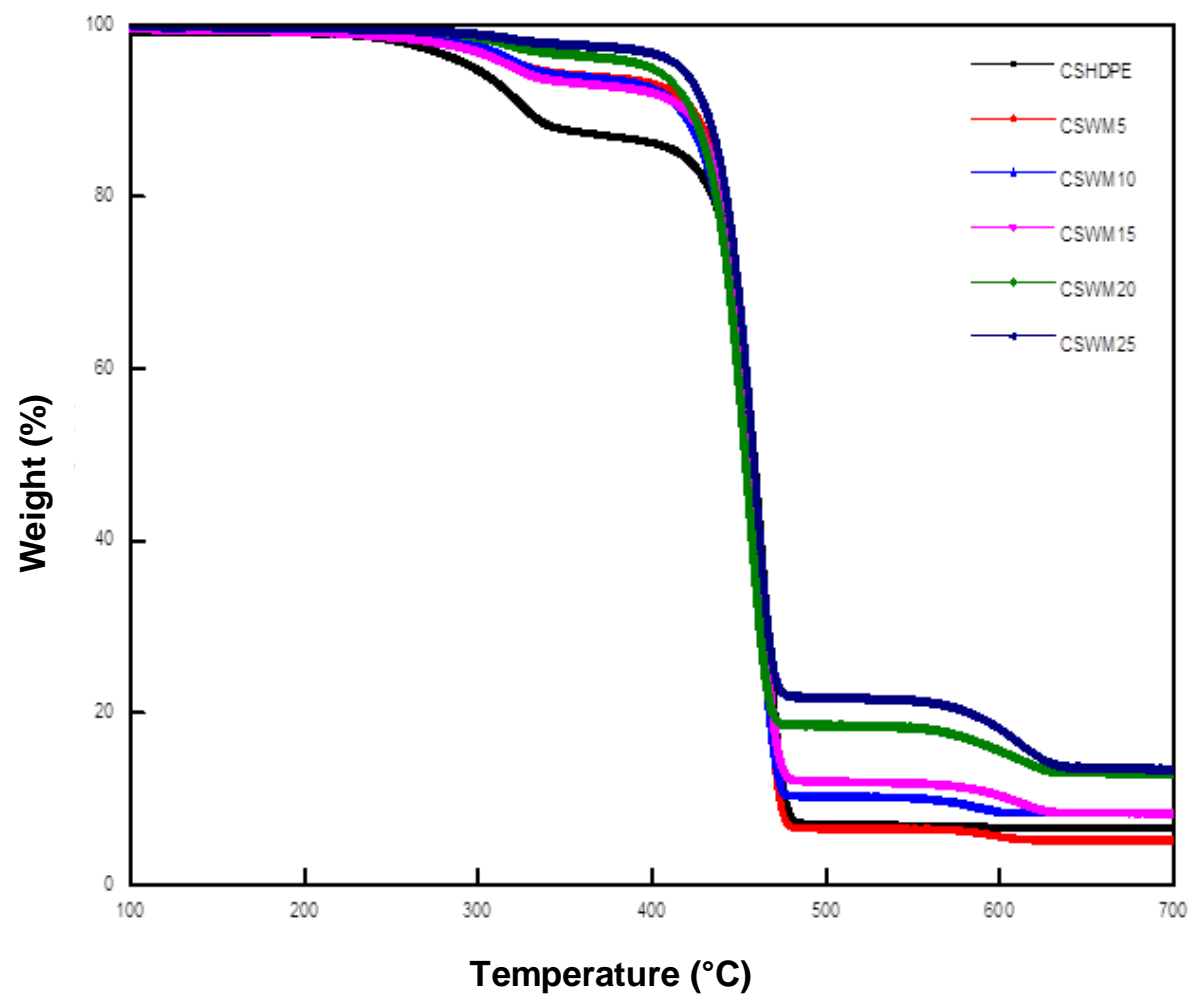




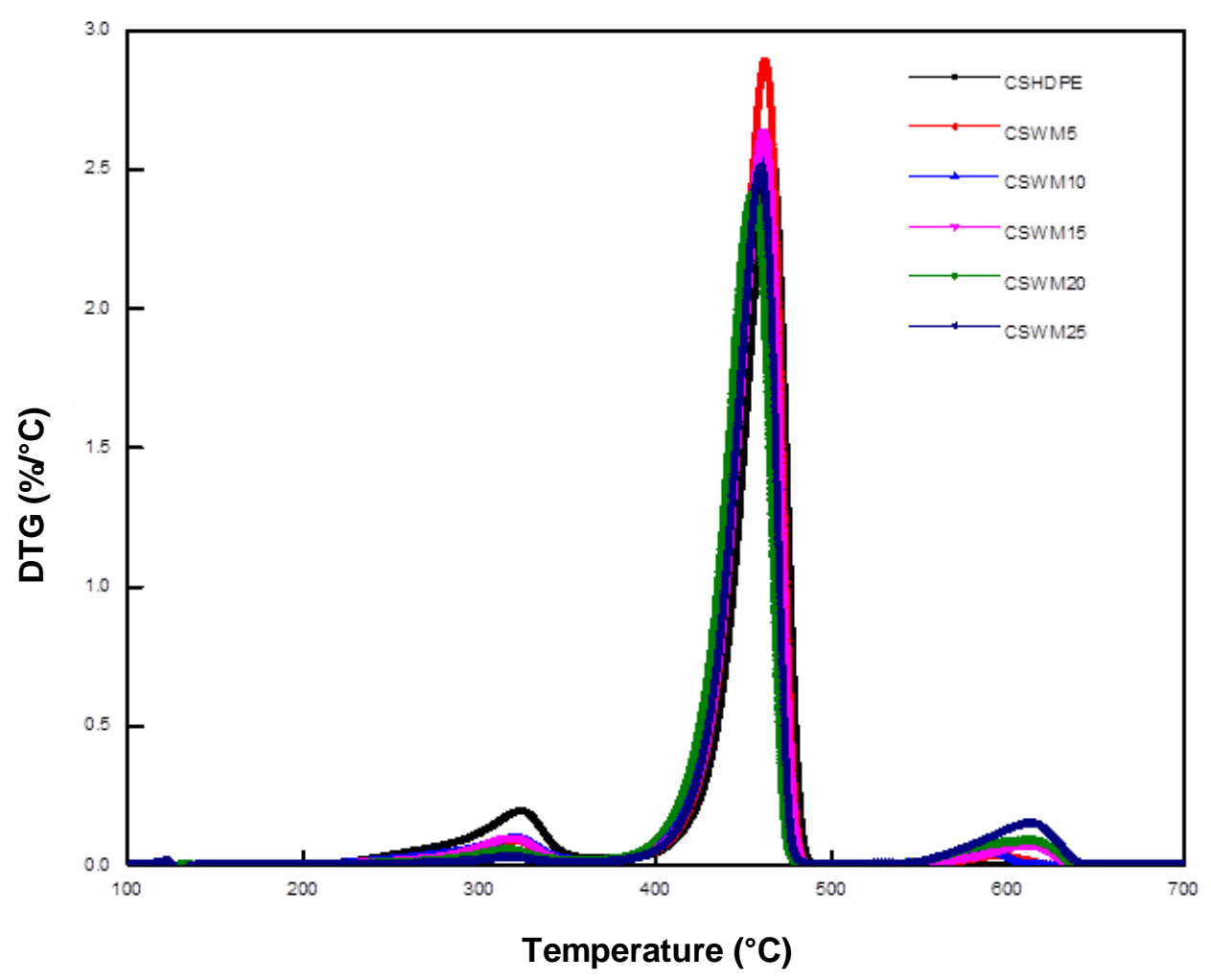

Fig. 1. The TGA and DTG curves of core-shell structured wood-plastic composites

The thermal decomposition parameters of core-shell structured wood-plastic composites were determined and are shown in Table 2. The initial decomposition temperature $\left(T_{5 \%}\right)$ is an important index to evaluate the thermal stability of composites, where a higher $T_{5} \%$ correlates with better thermal stability of the composites. The initial decomposition temperature, DTG peak temperature, and fixed carbon are listed in Table 2. There were obvious differences in the initial decomposition temperature and the first peak temperature with increased addition of white mud in the shell layer, indicating a remarkable influence of white mud on the thermal degradation behavior of composites. As expected, the authors observed higher initial decomposition temperature values with increased addition of white mud in the shell layer. This was likely because the amount of white mud increased and the amount of HDPE matrix decreased in the initial decomposition stage of composites, resulting in an increased initial decomposition temperature of composites. As the temperature continued to rise, numerous micro-pores formed as a result of the decomposition and gasification of the HDPE under the influence of heat, and the presence of these micro-pores accelerated the decomposition of HDPE. Therefore, the second and third temperature values of composites were less affected by the addition of white mud in the shell layer, and the peak temperatures exhibited a limited range of variation. The addition of white mud also affected the fixed carbon amount of the core-shell structured wood-plastic composites, and the fixed carbon amount of composites was markedly increased. The TGA and DTG curves for the core-shell structured wood-plastic composites and thermal decomposition parameters are presented in Table 2; the curves show that the addition of white mud in the shell improved the thermal stability of the composites. 
Table 2. Thermal Decomposition Parameters of Core-shell Structured Woodplastic Composites

\begin{tabular}{|c|c|c|c|c|c|}
\hline Sample & $T_{5 \%}\left({ }^{\circ} \mathrm{C}\right)$ & $T_{\mathrm{p} 1}\left({ }^{\circ} \mathrm{C}\right)$ & $T_{\mathrm{p} 2}\left({ }^{\circ} \mathrm{C}\right)$ & $T_{\mathrm{p} 3}\left({ }^{\circ} \mathrm{C}\right)$ & Fixed Carbon $(\%)$ \\
\hline CSHDPE & 312.6 & 333.3 & 479.5 & -- & 5.2 \\
\hline CSWM5 & 337.7 & 331.4 & 474.5 & 614.1 & 4.9 \\
\hline CSWM10 & 329.9 & 337.2 & 478.9 & 624.8 & 10.5 \\
\hline CSWM15 & 337.6 & 331.7 & 473.1 & 634.0 & 9.7 \\
\hline CSWM20 & 346.4 & 327.4 & 471.5 & 636.9 & 11.6 \\
\hline CSWM25 & 418.9 & 326.9 & 472.1 & 638.9 & 12.3 \\
\hline
\end{tabular}

$T_{5 \%}$ represents the initial decomposition temperature, defined as the temperature when there was a $5 \%$ decrease in weight; $T_{\mathrm{p} 1}, T_{\mathrm{p} 2}$, and $T_{\mathrm{p} 3}$ represent the first, second, and third peak temperature of DTG curves, respectively

\section{Kinetics of Core-shell Structured Wood-plastic Composites}

In this work, the FWO method was employed to calculate the activation energy. According to the results of previous studies on the pyrolysis of natural fiber reinforced composites and the pyrolysis of wood-plastic composites and wood-rubber composites (Yao et al. 2008; Ornaghi et al. 2014), it was found that the reaction mechanism of composites were different under the condition of low conversion rate $(10 \%)$ and high conversion rate (90\%). Therefore, the conversion rate of $20 \%$ to $80 \%$ was selected in this experiment. The $E_{a}$ value can be determined from the slope of the plot $\log \beta$ against $1 / T$. Figure $2 \mathrm{a}$ through $\mathrm{f}$ presents the plots between $\log \beta$ and $1 / T$ for various conversion rates of the core-shell structured wood-plastic composites. The values of $E_{\mathrm{a}}$ estimated using the isoconversional FWO method are shown in Fig. 2. The fitting lines of composites were almost parallel at the conversion rate of $20 \%$ to $80 \%$, indicating that the activation energy had no obvious change in this range, these results were consistent with previous studies (Mohomane et al. 2017; Wang et al. 2019). The kinetic parameters of the core-shell structured wood-plastic composites from the TGA data are listed in Table 3.

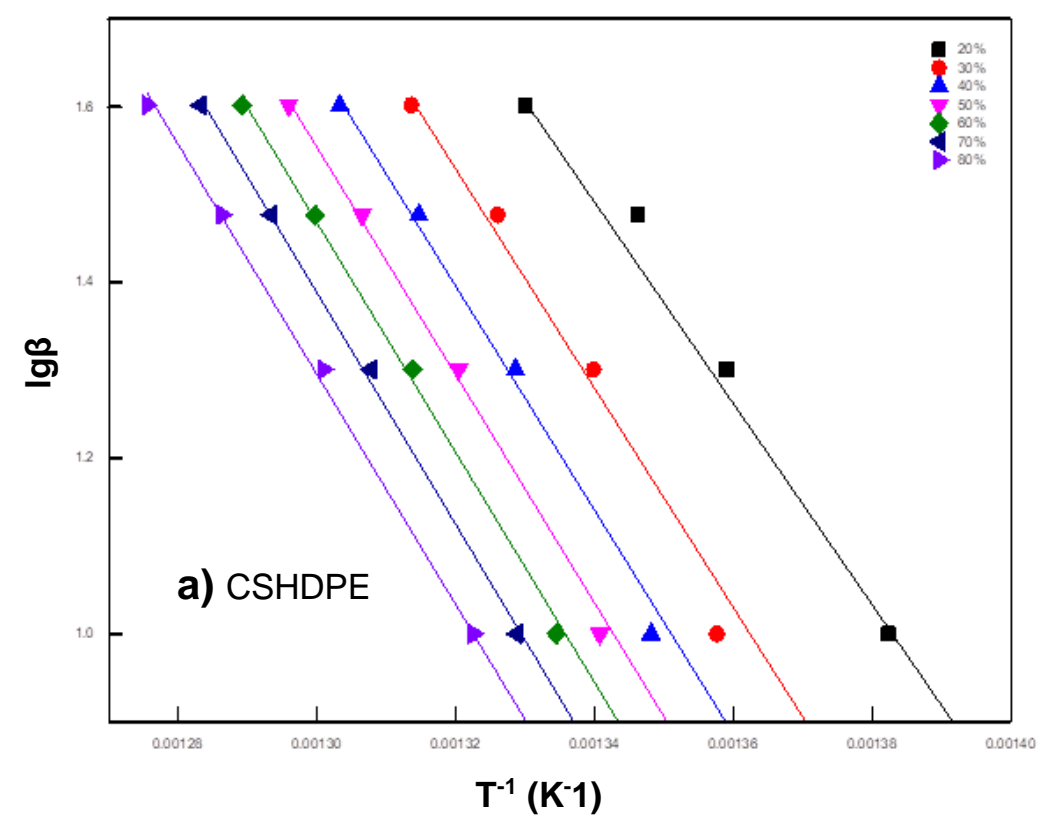

Xian et al. (2020). "WPC with white mud loading," BioResources 15(2), 2747-2762. 

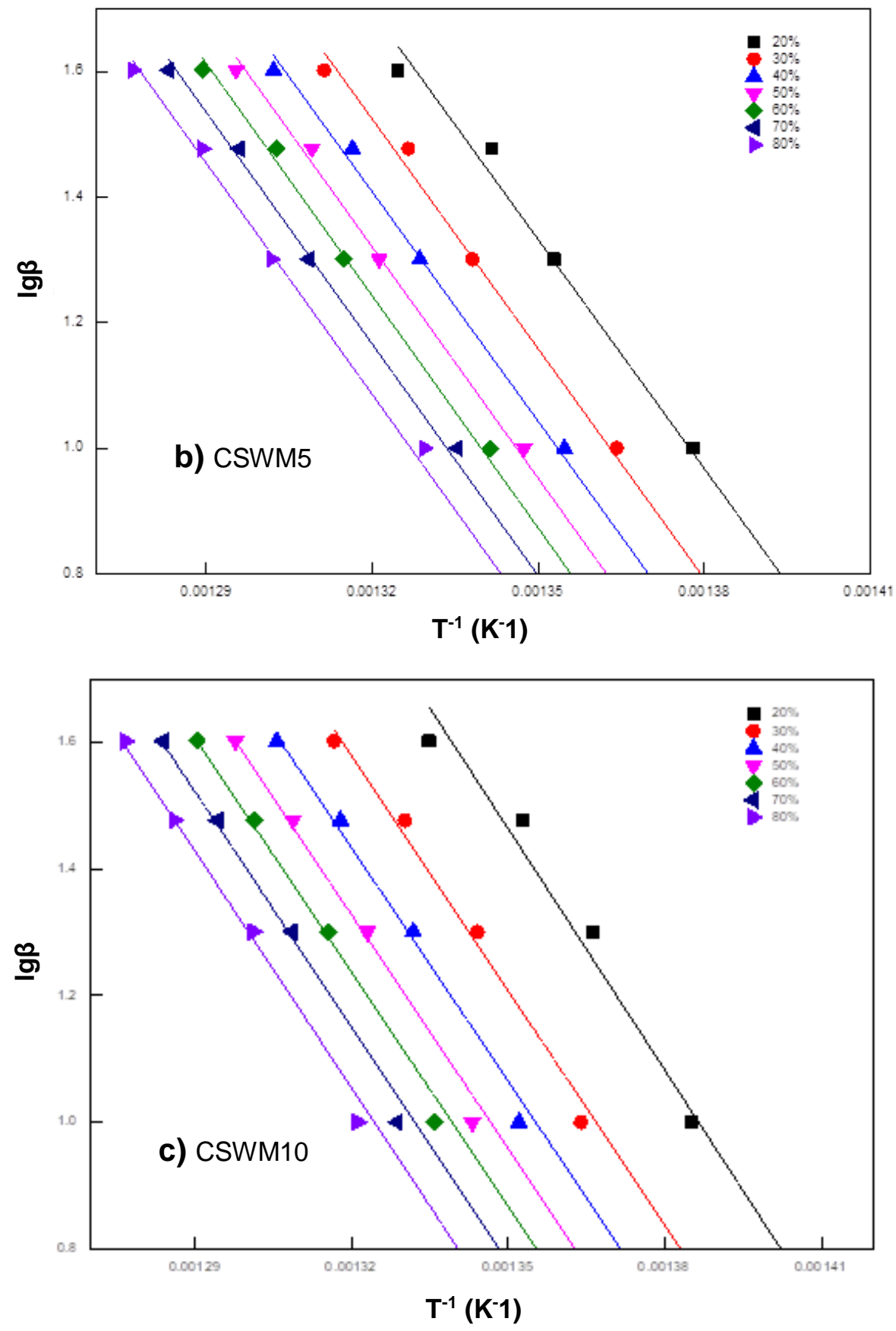

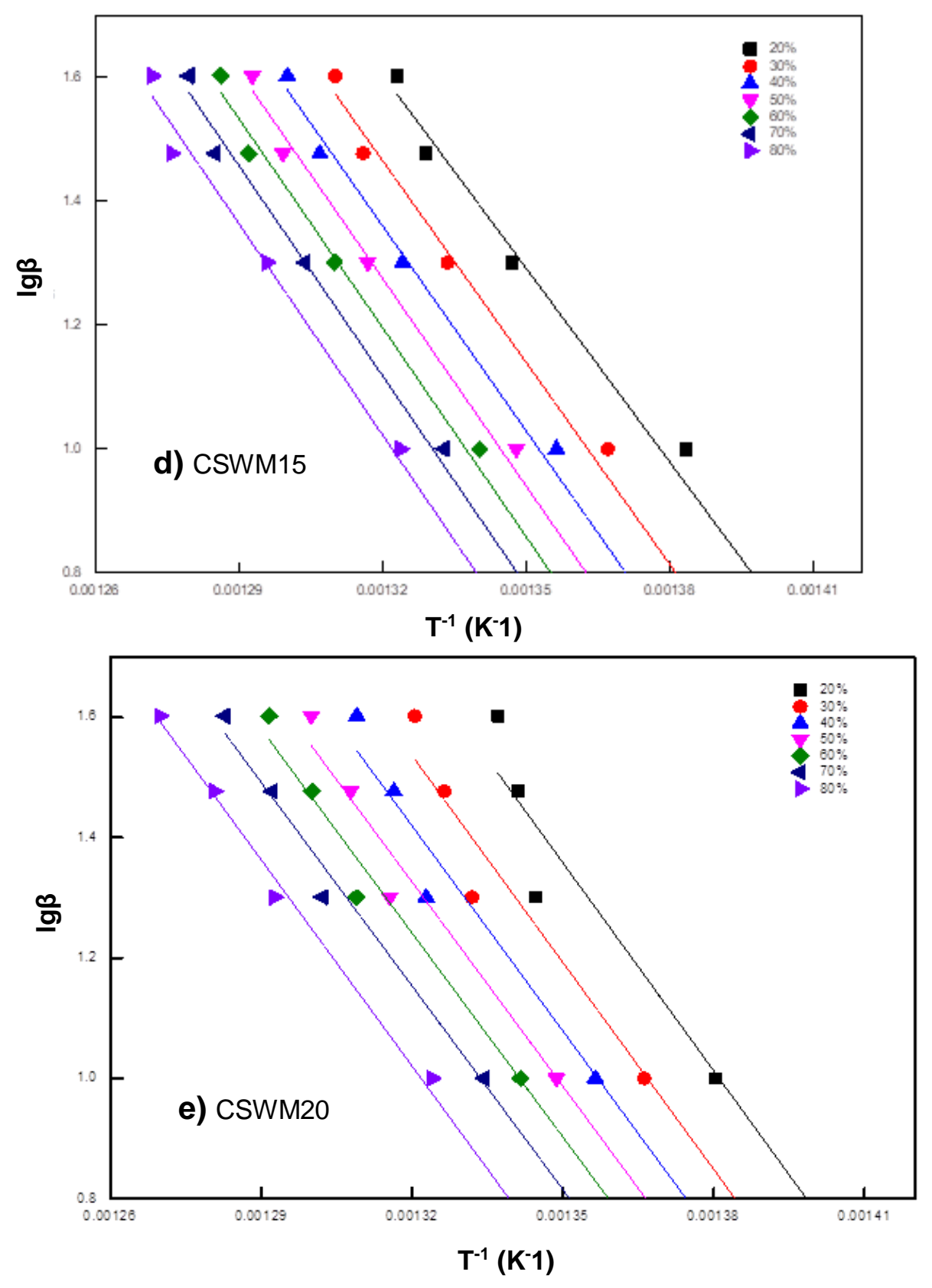


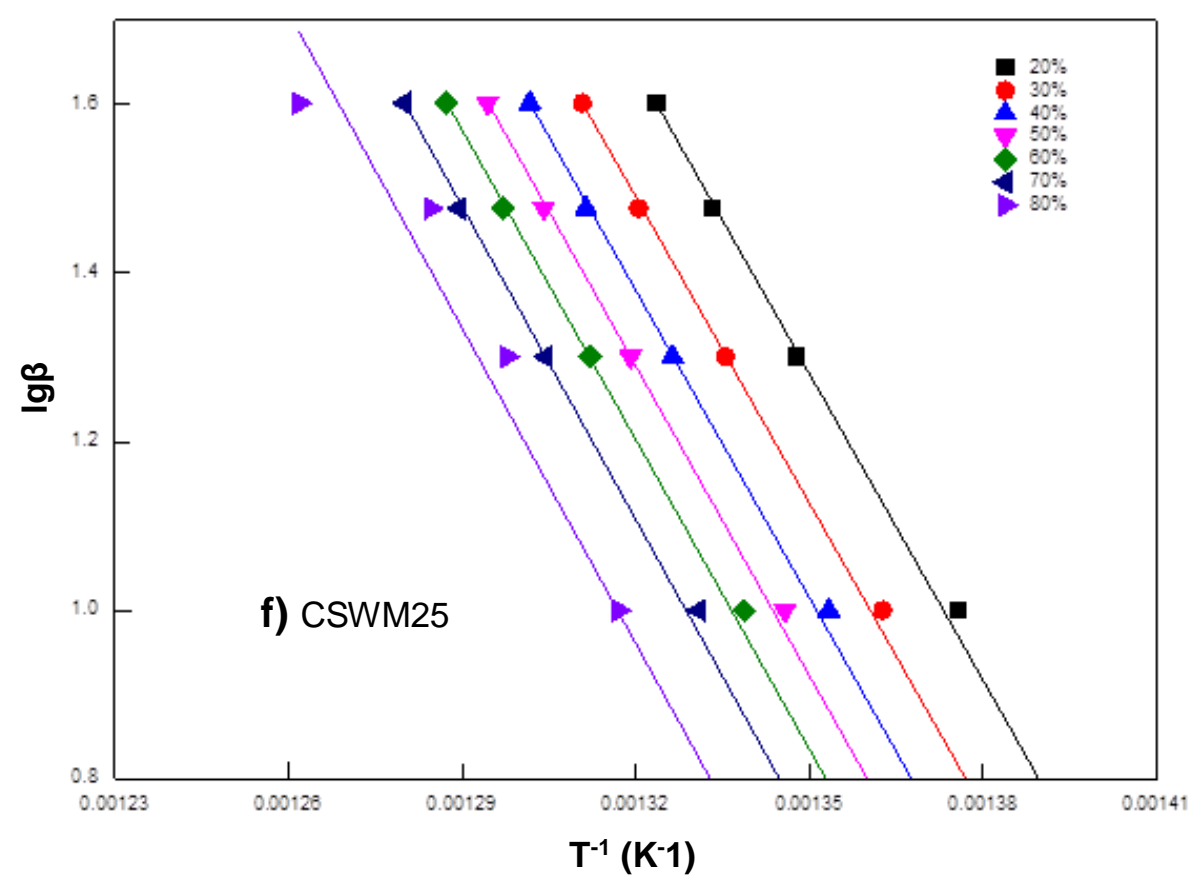

Fig. 2. The evaluated activation energy of core-shell structured wood-plastic composites by Flynn-Wall-Ozawa method. (a) CSHDPE (b) CSWM5 (c) CSWM10 (d) CSWM15 (e) CSWM20 (f) CSWM25

Table 3. Pyrolysis Kinetic Parameters of Core-Shell Structured Wood-plastic Composites at Different Heating Rates

\begin{tabular}{|c|c|c|c|c|c|}
\hline Sample & $B\left({ }^{\circ} \mathrm{C} / \mathrm{min}\right)$ & $T_{5 \%}\left({ }^{\circ} \mathrm{C}\right)$ & $T_{\mathrm{p}}\left({ }^{\circ} \mathrm{C}\right)$ & Fixed Carbon $(\%)$ & $E_{\mathrm{a}}\left(\mathrm{KJ} \cdot \mathrm{mol}^{-1}\right)$ \\
\hline & 10 & 312.6 & 479.5 & 5.2 & \\
CSHDPE & 20 & 327.1 & 490.0 & 4.4 & 221.58 \\
& 30 & 333.5 & 498.4 & 5.8 & \\
& 40 & 349.8 & 503.6 & 8.6 & \\
& 10 & 337.7 & 474.5 & 4.9 & \\
CSWM5 & 20 & 343.7 & 487.9 & 6.2 & \\
& 30 & 355.9 & 495.6 & 5.5 & \\
& 40 & 372.1 & 503.6 & 4.8 & \\
\hline & 10 & 329.9 & 478.9 & 10.5 & \\
CSWM10 & 20 & 338.8 & 490.1 & 7.4 & \\
& 30 & 345.5 & 498.1 & 9.4 & \\
& 40 & 351.4 & 505.1 & 6.9 & \\
CSWM15 & 10 & 337.6 & 473.1 & 9.7 & \\
& 20 & 361.9 & 490.6 & 7.9 & \\
& 30 & 395.9 & 500.4 & 11.1 & \\
\hline & 40 & 412.1 & 504.8 & 7.6 & \\
CSWM20 & 10 & 346.4 & 471.5 & 11.6 & \\
& 20 & 389.5 & 489.9 & 10.2 & \\
& 30 & 398.7 & 495.4 & 11.6 & \\
\hline \multirow{5}{*}{ CSWM25 } & 40 & 403.1 & 500.3 & 10.9 & \\
& 10 & 418.9 & 472.1 & 12.3 & \\
& 20 & 429.1 & 486.8 & 13.0 & \\
& 30 & 442.4 & 495.8 & 13.3 & \\
\hline
\end{tabular}


As shown in Table 3, the initial decomposition temperature of composites and the peak temperature increased with the increased heating rate. This was because it was easier to balance the composites at a certain temperature under the low heating rate, but when the heating rate increased, due to the relatively slow cooling process, the time required to reach equilibrium temperature increased, so the initial decomposition temperature was higher. Compared with the HDPE-shell composites, the initial decomposition temperature of composites also increased with the addition of white mud to the shell, indicating the effects of white mud on the thermal stability of core-shell structured wood-plastic composites. As expected, the authors observed a displacement of the curves to higher temperature values with the increase in heating rate $\beta$. This was mainly due to the increased hysteresis of the composite material to ambient temperature with increased heating rate, which increased the peak temperatures on the TGA curves.

Table 4. Values of $E_{\mathrm{a}}$ and $\mathrm{R}^{2}$ Obtained Using the FWO Method for Core-shell Structured Wood-plastic Composites

\begin{tabular}{|c|c|c|c|c|c|c|c|c|}
\hline Sample & $\alpha$ & 0.2 & 0.3 & 0.4 & 0.5 & 0.6 & 0.7 & 0.8 \\
\hline \multirow{2}{*}{ CSHDPE } & $E_{\mathrm{a}}\left(\mathrm{KJ} \cdot \mathrm{mol}^{-1}\right)$ & 210.50 & 209.18 & 232.74 & 236.16 & 220.13 & 221.94 & 220.41 \\
\hline & $\mathrm{R}^{2}$ & 0.9500 & 0.9873 & 0.9949 & 0.9976 & 0.9987 & 0.9991 & 0.9986 \\
\hline \multirow{2}{*}{ CSWM5 } & $E_{\mathrm{a}}\left(\mathrm{KJ} \cdot \mathrm{mol}^{-1}\right)$ & 221.13 & 221.88 & 221.72 & 223.62 & 224.48 & 223.84 & 223.34 \\
\hline & $\mathrm{R}^{2}$ & 0.9910 & 0.9943 & 0.9959 & 0.9964 & 0.9963 & 0.9964 & 0.9954 \\
\hline \multirow{2}{*}{ CSWM10 } & $E_{\mathrm{a}}\left(\mathrm{KJ} \cdot \mathrm{mol}^{-1}\right)$ & 231.27 & 225.09 & 223.69 & 224.23 & 224.48 & 225.58 & 226.72 \\
\hline & $\mathrm{R}^{2}$ & 0.9810 & 0.9932 & 0.9942 & 0.9939 & 0.9941 & 0.9943 & 0.9944 \\
\hline \multirow{2}{*}{ CSWM15 } & $E_{\mathrm{a}}\left(\mathrm{KJ} \cdot \mathrm{mol}^{-1}\right)$ & 189.77 & 197.70 & 200.66 & 203.23 & 204.65 & 205.82 & 206.75 \\
\hline & $\mathrm{R}^{2}$ & 0.9810 & 0.9932 & 0.9942 & 0.9939 & 0.9941 & 0.9943 & 0.9944 \\
\hline \multirow{2}{*}{ CSWM20 } & $E_{\mathrm{a}}\left(\mathrm{KJ} \cdot \mathrm{mol}^{-1}\right)$ & 209.64 & 208.44 & 206.71 & 205.81 & 205.54 & 205.15 & 207.79 \\
\hline & $\mathrm{R}^{2}$ & 0.9401 & 0.9616 & 0.9715 & 0.9789 & 0.9849 & 0.9904 & 0.9954 \\
\hline \multirow{2}{*}{ CSWM25 } & $E_{\mathrm{a}}\left(\mathrm{KJ} \cdot \mathrm{mol}^{-1}\right)$ & 220.69 & 220.45 & 221.37 & 222.79 & 222.89 & 225.51 & 227.15 \\
\hline & $\mathrm{R}^{2}$ & 0.9967 & 0.9974 & 0.9975 & 0.9975 & 0.9972 & 0.9968 & 0.9515 \\
\hline
\end{tabular}

Table 4 presents the activation energy values for core-shell structured wood-plastic composites prepared with different concentrations of white mud in the shell layer. The activation energy values of CSWM10 were slightly higher than other composites. This was ascribed to the quantum size effect and specific surface area effect of micro-nano white mud particles, which increased the force and contact area between white mud and HDPE, thereby increasing the average apparent activation energy of the core-shell structured wood-plastic composites system to some extent. With increased mass fraction of white mud in composites, the average apparent activation energy values of composites decreased. This may be because the introduction of white mud in composites could affect flexibility of HDPE molecule chains during the process of melt blending and extrusion forming for preparing wood-plastic composites, which increased the random distribution of the HDPE molecular chains, leading to the decrease of the crystallinity. However, the crystallinity of HDPE had an important impact on the properties of composites. The strength and thermal resistance of HDPE composites weakened with decreased crystallinity. In addition, recent studies have revealed that the interface of wood-plastic composites has an effect on thermal stability; a good interfacial bonding of wood-plastic composites is favorable for improving the thermal stability (Avella et al. 2010; Shi et al. 2013). The addition of too much white 
mud may lead to incomplete interfacial bonding of the core and shell, resulting in the reduced thermal stability of composites, which had a smaller activation energy. the activation energy implied that the ignition of core-shell structured wood-plastic composites in fire is easy.

\section{Thermal Aging Life of Core-shell Structured Wood-plastic Composites}

For composites, the service life $t_{\mathrm{f}}(\mathrm{min})$ is usually determined by the failure time of thermal property. For TG analysis, the temperature of 5\% weight loss in TG experiments has been widely used to evaluate the service life of composites (Mothe and De Freitas 2018). Thermal aging life equations were established by the method described in ASTM E1877 (2000), and the life equation is as follows,

$$
\log t_{\mathrm{f}}=E /\left(2.303 R T_{\mathrm{f}}\right)+\log (E / R \beta)-a
$$

where $t_{\mathrm{f}}$ is service life under a given conversion rate, $E$ is apparent activation energy (in units of $\left.\mathrm{Jmol}^{-1}\right), R$ is the gas constant $\left(8.314 \mathrm{JK}^{-1} \mathrm{~mol}^{-1}\right), T_{\mathrm{f}}$ is failure temperature $(\mathrm{K})$ under the given conversion rate, $\beta$ is the constant heating rate, and $a$ represents the integration constant, which is obtained from the ASTM E1641-07 (2007).

The activation energy values of the core-shell structured wood-plastic composites were obtained by TGA. The value of constant $a$ is determined according to the ASTM E1641-07 (2007). The authors calculated the thermal aging life of the core-shell structured wood-plastic composites as shown in Fig. 3 below.

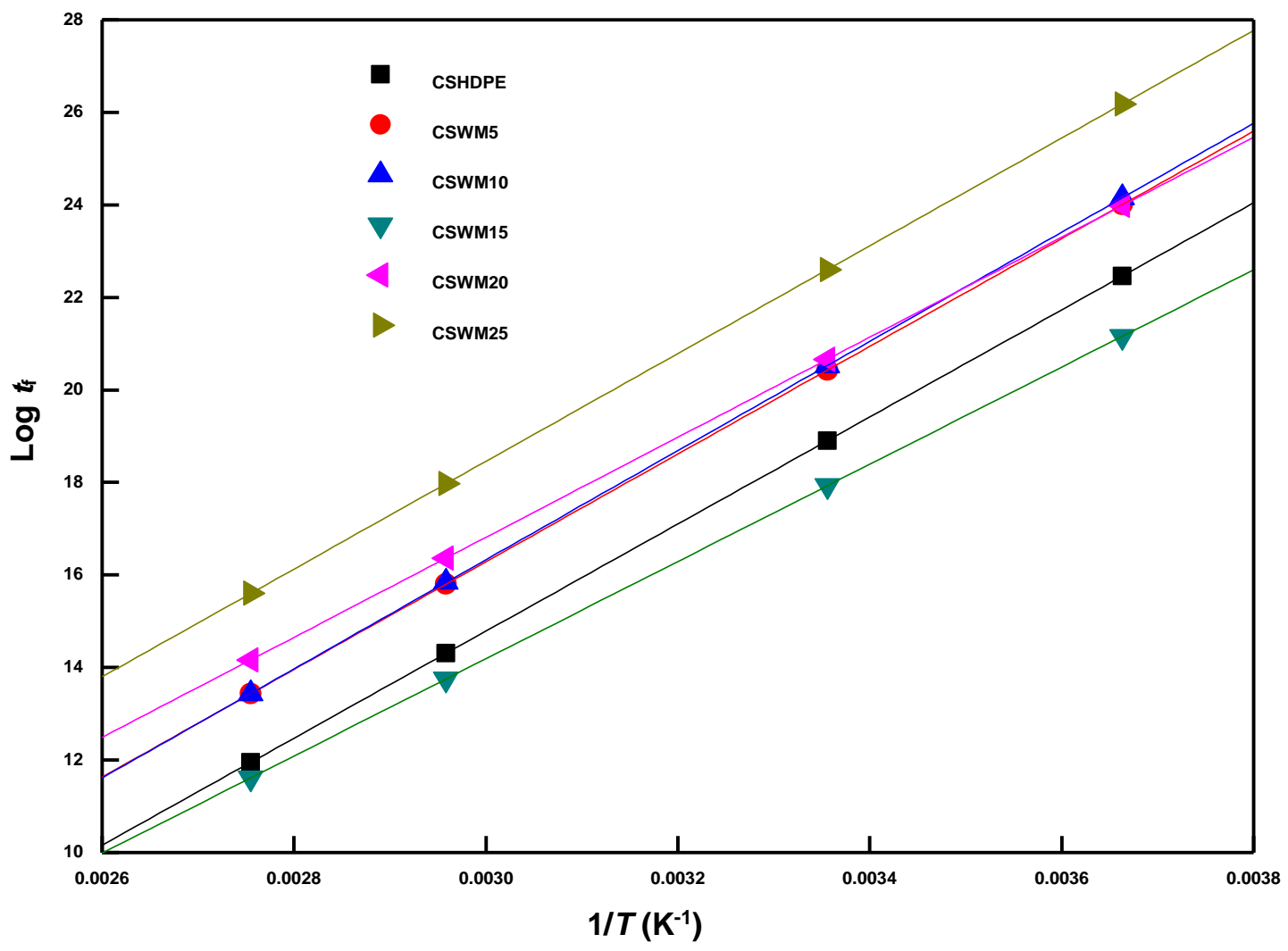

Fig. 3. The relation equation of the service life $t_{f}(\mathrm{~min})$ and the service temperature $T(\mathrm{~K})$ 
As shown in Fig. 3, the thermal aging life of core-shell structured wood-plastic composites can be estimated at any temperature, or limit service temperature for arbitrary aging life. It can be seen that the service life of core-shell structured wood-plastic composites was highly dependent on temperature from Eq. 6 and Fig. 3, and the service life of composites dropped sharply with the increase of service temperature.

\section{CONCLUSIONS}

1. The effects of white mud on thermal degradation kinetics and thermal aging life of core shell structured wood-plastic composites were studied with the aid of TGA. The TGA results showed the composites combustion process were divided into three stages, the trend of combustion characteristic parameters $\left(T_{5 \%}, T_{\mathrm{p} 1}, T_{\mathrm{p} 2}\right.$, and $\left.T_{\mathrm{p} 3}\right)$ increased at first and then descended with increased white mud concentration. The displacement of the whole TG and DTG curves for core-shell structured wood-plastic composites shifted to higher temperature at heating rates of $5,10,20,30$, and $40{ }^{\circ} \mathrm{C} / \mathrm{min}$ under nitrogen atmosphere. Additionally, compared with the shell for HDPE composites, the initial decomposition temperature of the composites increased with the addition of white mud in the shell layer, but the peak temperature was almost unchanged, the results showed that the addition of white mud had little impact on the thermal stability of the core-shell structured wood-plastic composites.

2. The activation energy was evaluated using the FWO method, compared with the pure HDPE shell layer, the average apparent activation energy of the composites slightly lowered as the addition of white mud increased in the shell, and there was no obvious influence on composites under this experimental condition. This was beneficial to improve the physical and mechanical properties using the white mud, that is, the thermal stability of the composites will not be affected within the range of the test.

3. The parameters ( $T$ and $E$ ) of the composites at $5 \%$ weightlessness were fitted and the relationship between service life and temperature was obtained. The thermal aging life equations of composites were obtained from the method described in ASTM E1877 (2000). Therefore, the service life of the core-shell structured wood-plastic composites can be predicted at different temperatures.

\section{ACKNOWLEDGMENTS}

This work was supported by the National Key R\&D Program of China (No. 2017YFD0600802), the foundation for Shanxi Province Excellent Doctors (SXYBKY201745), the Technology and Innovation Fund of Shanxi Agricultural University (2017YJ23), and the Scientific and Technological Innovation Program of Higher Education Institutions in Shanxi (2019L0395). The authors would like to express sincere thanks to Shanxi Agricultural University and the State Forestry Administration Key Laboratory for Bamboo and Rattan Science and Technology. 


\section{REFERENCES CITED}

ASTM E1641-07 (2007). "Characterization and lifetime estimation of high-density polyethylene containing a prodegradant agent," ASTM International, West Conshohocken, PA, USA.

ASTM E1877 (2000). "Standard practice for calculating thermal endurance of materials from thermogravimetric decomposition data," ASTM International, West Conshohocken, PA, USA.

Avella, M., Avolio, R., Bonadies, I., Carfagna, C., Errico, M. E., and Gentile, G. (2010). "Effect of compatibilization on thermal degradation kinetics of HDPE-based composites containing cellulose reinforcements," Journal of Thermal Analysis and Calorimetry 102(3), 975-982. DOI: 10.1007/s10973-010-0836-3

Constante, A., and Pillay, S. (2017). "Algae fiber polypropylene composites: Modeling of the degradation by solid state kinetics," Journal of Applied Polymer Science 134(12), Article ID 44622. DOI: 10.1002/app.44622

Dun, M., Hao, J., Wang, W., Wang, G., and Cheng, H. (2019). "Sisal fiber reinforced high density polyethylene pre-preg for potential application in filament winding," Composites Part B: Engineering 159, 369-377. DOI:

10.1016/j.compositesb.2018.09.090

Friedrich, D. (2019). "Effects from natural weathering on long-term structural performance of wood-polymer composite cladding in the building envelope," Journal of Building Engineering 23, 68-76. DOI: 10.1016/j.jobe.2019.01.025

Hao, X., Zhou, H., Xie, Y., Xiao, Z., Wang, H., and Wang, Q. (2019). "Mechanical reinforcement and creep resistance of coextruded wood flour/polyethylene composites by shell-layer treatment with nano- and micro-SiO 2 particles," Polymer Composites 40(4), 1576-1584. DOI: 10.1002/pc.24901

Huang, R., Mei, C., Xu, X., Kaerki, T., Lee, S., and Wu, Q. (2015). "Effect of hybrid talc-basalt fillers in the shell layer on thermal and mechanical performance of coextruded wood plastic composites," Materials 8(12), 8510-8523. DOI: $10.3390 / \mathrm{ma} 8125473$

Ismaeilimoghadam, S., Masoudifar, M., Nosrati, B., and Shamsian, M. (2016). "Effects of inorganic nanoparticles on mechanical and morphological properties of wood flour-polypropylene nano composites," Drewno 59(196), 127-137. DOI: 10.12841/wood.1644-3985.127.09

Kim, B. J. (2014). "Overview of wood plastic composites: Focusing on use of bio-based plastics and co-extrusion technique," Journal of the Korean Wood Science and Technology 42(5), 499-509. DOI: 10.5658/WOOD.2014.42.5.499

Li, Y. J., Sun, R. Y., Zhao, J. L., Han, K. H., and Lu, C. M. (2012). "Sulfation behavior of white mud from paper manufacture as $\mathrm{SO}_{2}$ sorbent at fluidized bed combustion temperatures," Journal of Thermal Analysis and Calorimetry 107(1), 241-248. DOI: 10.1007/s10973-011-1537-2

Liu, C., Mei, C., Xu, B., Jiang, M., Chen, W., Zhou, G., and Wang, K. (2019). "Effect of the nanosilica content in the shell of coextruded wood-plastic composites to enhance the ultraviolet aging resistance," Polymers for Advanced Technologies 30(1), 162169. DOI: $10.1002 /$ pat. 4454

Masawat, N., Atong, D., and Sricharoenchaikul, V. (2019). "Thermo-kinetics and product analysis of the catalytic pyrolysis of Pongamia residual cake," Journal of Environmental Management 242, 238-245. DOI: 10.1016/j.jenvman.2019.04.080 
Mittal, P., Naresh, S., Luthra, P., Singh, A., Dhaliwal, J. S., and Kapur, G. S. (2019). "Polypropylene composites reinforced with hybrid inorganic fillers: Morphological, mechanical, and rheological properties," Journal of Thermoplastic Composite Materials 32(6), 848-864. DOI: 10.1177/0892705718785674

Mohanty, A. K., Vivekanandhan, S., Pin, J. M., and Misra, M. (2018). "Composites from renewable and sustainable resources: Challenges and innovations," Science 362(6414), 536-542. DOI: 10.1126/science.aat9072

Mohomane, S. M., Motaung, T. E., and Revaprasadu, N. (2017). "Thermal degradation kinetics of sugarcane bagasse and soft wood cellulose," Materials 10(11), Article Number 1246. DOI: 10.3390/ma10111246

Mothe, C. G., and De Freitas, J. S. (2018). "Lifetime prediction and kinetic parameters of thermal decomposition of cashew gum by thermal analysis," Journal of Thermal Analysis and Calorimetry 131(1), 397-404. DOI: 10.1007/s10973-017-6844-9

Ornaghi, H. L., Poletto, M., Zattera, A. J., and Amico, S. C. (2014). "Correlation of the thermal stability and the decomposition kinetics of six different vegetal fibers," Cellulose 21(1), 177-188. DOI: 10.1007/s10570-013-0094-1

Ren, W., Zhang, D., Wang, G., and Cheng, H. (2014). "Mechanical and thermal properties of bamboo pulp fiber reinforced polyethylene composites," BioResources 9(3), 4117-4127. DOI: 10.15376/biores.9.3.4117-4127

Satapathy, S., and Kothapalli, R. V. S. (2018). "Mechanical, dynamic mechanical and thermal properties of banana fiber/recycled high density polyethylene biocomposites filled with flyash cenospheres," Journal of Polymers and the Environment 26(1), 200213. DOI: $10.1007 / \mathrm{s} 10924-017-0938-0$

Shi, X. B., Wang, J. L., Cai, X. P., and Zhang, S. (2013). "Role of calcium carbonate morphology on thermal and mechanical properties of HDPE," Plastics Rubber and Composites 42(7), 302-307. DOI: 10.1179/1743289813Y.0000000051

Sun, L., Wu, Q., Xie, Y., Cueto, R., Lee, S., and Wang, Q. (2016). "Thermal degradation and flammability behavior of fire-retarded wood flour/polypropylene composites," Journal of Fire Sciences 34(3), 226-239. DOI: 10.1177/0734904116637632

TranVan, L., Legrand, V., and Jacquemin, F. (2014). "Thermal decomposition kinetics of balsa wood: Kinetics and degradation mechanisms comparison between dry and moisturized materials," Polymer Degradation and Stability 110, 208-215. DOI: 10.1016/j.polymdegradstab.2014.09.004

Wang, C., Wang, X., Jiang, X., Li, F., Lei, Y., and Lin, Q. (2019). "The thermal behavior and kinetics of co-combustion between sewage sludge and wheat straw," Fuel Processing Technology 189, 1-14. DOI: 10.1016/j.fuproc.2019.02.024

Xian, Y., Li, H., Wang, C., Wang, G., Ren, W., and Cheng, H. (2015). "Effect of white mud as a second filler on the mechanical and thermal properties of bamboo residue fiber/polyethylene composites," BioResources 10(3), 4263-4276. DOI: 10.15376/biores.10.3.4263-4276

Xian, Y., Ma, D., Wang, C., Wang, G., Smith, L., and Cheng, H. (2018). "Characterization and research on mechanical properties of bamboo plastic composites," Polymers 10(8), Article Number 814. DOI: 10.3390/polym10080814

Xian, Y., Wang, C., Wang, G., Ren, W., and Cheng, H. (2016). "Understanding the mechanical and interfacial properties of core-shell structured bamboo-plastic composites," Journal of Applied Polymer Science 133(10), Article ID 43053. DOI: 10.1002/app.43053 
Yao, F., and Wu, Q. (2010). "Coextruded polyethylene and wood-flour composite: Effect of shell thickness, wood loading, and core quality," Journal of Applied Polymer Science 118(6), 3594-3601. DOI: 10.1002/app.32742

Yao, F., Wu, Q., Lei, Y., Guo, W., and Xu, Y. (2008). "Thermal decomposition kinetics of natural fibers: Activation energy with dynamic thermogravimetric analysis," Polymer Degradation and Stability 93(1), 90-98. DOI: 10.1016/j.polymdegradstab.2007.10.012

Yi, X., Zhao, D., Ou, R., Ma, J., Chen, Y., and Wang, Q. (2017). "A comparative study of the performance of wood-plastic composites and typical substrates as heating floor," Bioresources 12(2), 2565-2578. DOI: 10.15376/biores.12.2.2565-2578

Article submitted: November 11, 2019; Peer review completed: February 13, 2020; Revised version received: February 23, 2020; Accepted: February 24, 2020; Published: March 2, 2020.

DOI: 10.15376/biores.15.2.2747-2762 